cần rửa tay đúng $99,7 \%$, các triệu chứng nghi ngờ mắc COVID-19 đúng 99,6\%. Tuy nhiên, các kiến thức về thời gian tôn tại của virus Corona trong không khí và trên bề mặt nào lâu nhất có tỉ lệ đúng còn thấp lần lượt là: $33,9 \%$ và $57,2 \%$.

Nghiên cứu thu thập số liệu ở đợt bùng phát dịch lần thứ nhất tại Việt Nam, trong đó Hà Nội có số ca lây nhiễm cao so với các tỉnh khác ở đợt này. Kết quả nghiên cứu cho thấy hầu hết NVYT đã cập nhật kiến thức về COVID-19 kịp thời, tác dụng của việc truyên thông của Bộ Y tế qua các buổi tập huẩn, tài liệu phát tay, qua các phương tiên thông tin đại chúng là có hiệu quả tốt nên kiến thức về COVID-19 của NVYT tại tuyến YTCS của Hà Nội khá cao. Kết quả nghiên cứu này cung cấp bằng chứng cho thấy đội ngũ NVYT cơ sở có sự chuẩn sẵn sàng về kiến thức cho công tác phòng chống đại dịch COVID-19 trong tình hình dịch bệnh vẫn còn đang căng thẳng hiện nay. Đây chính là một trong những lí do góp phần vào sự thành công của việc phòng chống dịch COVID-19 của thành phố Hà Nội nói riêng và của Việt Nam nói chung. Bên cạnh đó, vẫn còn một số kiến thức có tỉ lệ trả lời đúng tương đối thấp như: thời gian virus corona tồn tại trong không khí và trên bề mặt nào lâu nhất, vấn đề này cũng rất quan trọng trong việc phòng tránh lây nhiễm bệnh, vì vậy vẫn cần cung cấp thêm thông tin về những khía cạnh này của COVID-19 cho NVYT cơ sở để việc phòng tránh dịch bệnh đạt hiệu quả cao hơn nữa, vì đây là một "mắt xích" rất quan trọng - là tuyến đầu chống dịch với vai trò: truyền thông trong cộng đồng, truy vết phát hiện sớm ca nhiễm, quản lí các đối tượng nguy cơ tại cộng đồng.

\section{KẾT LUÂN}

- Độ tuổi trung bình của các NVYT tại tuyến cơ sở là 38,8 $\pm 9,2$, thâm niên công tác trung bình là 13,8 năm, nhân viên nữ chiếm $75 \%$

- Kiến thức về COVID-19 của nhân viên y tế tuyến cơ sở tại Hà Nội đạt tương đối cao. Có $64 \%$ số NVYT trả lời đúng được 70-90\% số câu hỏi về COVID-19. Tỷ lệ trả lời đúng trên $90 \%$ số câu hỏi đạt tỷ lệ là $34 \%$.

- Chưa thấy sự khác biệt về kiến thức COVID19 theo một số đặc điểm chung như giới tính, nhóm tuổi và thâm niên công tác.

\section{TÀI LIÊU THAM KHẢO}

1. WHO (2020). Director-General's opening remarks at the media briefing on COVID-19 - 11 March 2020, 21/06/2021.

2. Bô Y $\mathbf{Y}$ tế (2021). Trang tin về dich bệnh viêm đường hô hấp cấp COVID-19, <https:// ncov.moh.gov.vn/ >, 21/06/2021.

3. Huynh G, Nguyen T.N.H, Tran V.K et al (2020). Knowledge and attitude toward COVID-19 among healthcare workers at District 2 Hospital, Ho Chi Minh City. Asian Pac J Trop Med, 13, 52-58.

4. Mohammed Basheeruddin Asdaq S., A.S A., Imran Mohd. et al (2021). Knowledge, attitude and practices of healthcare professionals of Riyadh, Saudi Arabia towards covid-19: A crosssectional study. Saudi J Biol Sci, 15, 30-47.

5. Hossain M.A., Rashid M.U.B., Khan M.A.S. et al (2021). Healthcare Workers' Knowledge, Attitude, and Practice Regarding Personal Protective Equipment for the Prevention of COVID19. J Multidiscip Healthc, 14, 229-238.

6. Tien T.Q., Tuyet-Hanh T.T., Linh T.N.Q. et al (2021). Knowledge, Attitudes, and Practices Regarding COVID-19 prevention among Vietnamese Healthcare Workers in 2020. Health Serv Insights, 14, 34-40.

7. Bhagavathula A.S, Aldhaleei W.A, Rahmani J et al (2020). Knowledge and Perceptions of COVID-19 Among Health Care Workers: Cross-Sectional Study. JMIR Public Health Surveill, 6(2), e19160, 40-45.

8. Zhang $M$, Zhou $M$, Tang $F$ et al (2020). Knowledge, attitude, and practice regarding COVID-19 among healthcare workers in Henan, China. J Hosp Infect, 105(2), 183-187.

\title{
KHẢO SÁT THỰC TRANG CHẤT LƯợNG GIẤC NGỦ Ở NGƯờI BÊNH TĂNG HUYẾT ÁP TẠI XÃ NAM PHONG, THÀNH PHỐ NAM ĐỊNH, NĂM 2019
}

\section{TÓM TẮT}

\footnotetext{
*Trường Đại họ Điều dưỡng Nam Định Chịu trách nhiệm chính: Nguyễn Thị Huễ Email: huedhdd@gmail.com Ngày nhận bài: 6.5 .2021 Ngày phản biện khoa học: 24.6.2021 Ngày duyệt bài: 5.7.2021
}

\section{Nguyễn Thị Huế*, Đinh Thị Phương Hoa*}

Nghiên cứu mô tả cắt ngang nhằm mục tiêu mô tả thực trạng chất lượng giấc ngủ (CLGN) ở người bệnh tăng huyết áp tại xã Nam Phong, thành phố Nam Định năm 2019. Nghiên cứu sử dụng bộ công cụ đánh giá chất lượng giấc ngủ Pittsburgh Sleep Quality Index (PSQI) đã được dịch sang tiếng việt và được kiểm định lại độ tin cây trước khi thu thập số liệu chính thức. Phướng pháp chọn mẫu toàn bộ và phỏng vấn trực tiếp được áp dụng để thu thập số liệu trong nghiên cứu. Kết quả thu được có 49,3\% đối tượng cần 
từ 15-30 phút để đi vào giấc ngủ. Tỷ lệ đối tượng ngủ được 5-6 tiếng/đêm chiếm $31,8 \%$ và ít hơn 5 tiếng/đêm chiếm 37,2\%. Có lần lượt $20,3 \%$ và 39,9\% đối tượng có hiêuu suất giấc ngủ tương đối kém và kém. Có $52 \%$ đối tượng phải sử dụng thuốc ngủ để có giấc ngủ tốt hơn. 53,4\% đối tượng gặp khó khăn ở mức độ nhẹ trong các hoạt động hàng ngày do tình trạng thiếu ngủ; 53,4\% tự đánh giá rằng mình có chất lượng giấc ngủ tương đối kém và $3,4 \%$ cho rằng chất lượng giấc ngủ của mình rất kém. Đánh giá chất lươnng giấc ngủ theo thang PSQI cho kết quả có 95,9 đối tượng có chất lượng giấc ngủ kém và $4,1 \%$ có chất lượng giấc ngủ tổt. Từ kết quả nghiên cứu chúng tôi kết luâan rằng chất lượng giấc ngủ kém là hiện tượng phổ biến, thường gặp ở bệnh nhân có tăng huyết áp tại xã Nam Phong, thành phố Nam Định. Từ đó chúng tôi khuyến nghị cần có những chương trình can thiệp nhằm giúp nâng cao chất lượng giấc ngủ của bệnh nhân tăng huyết áp tại xã Nam Phong, thành phố Nam Định.

Tư khoá: chất lượng giấc ngủ, tăng huyết áp, xã Nam Phong, Nam Định

\section{SUMMARY \\ SURVEY OF SLEEPING QUALITY AMONG PATIENTS WITH HYPERTENSION IN NAM PHONG COMMUNE, NAM DINH CITY, IN 2019}

A cross-sectional study aimed at describing sleeping quality of patients with hypertension in Nam Phong commune, Nam Dinh city, in 2019. The study utilized Pittsburgh Sleep Quality Index (PSQI) to screen sleeping qualify of participants, which was translated into Vietnamese and measured internal consistency before officially data collecting. All patients with hypertension in the research place were selected to take part in the survey, and face-to-face interviews were deployed. The result shows that $49.3 \%$ of respondents need from 15 to 30 minutes to start sleeping. The participants who slept from 5 to 6 hours per night accounted for $31.8 \%$ and less than 5 hours per night took $37.2 \%$. Those with low and very low habitual sleep efficiency hold $20.3 \%$ and $39.9 \%$ respectively. There were $52 \%$ of participants sought help from sleeping pills to sleep better at night. $53.4 \%$ reported that they experienced little difficulties in daytime activities due to sleep deficiency. $53.4 \%$ of respondents self-evaluated that they had a fairly poor sleeping quality and 3,4\% reported that they thought their sleep quality was very poor. The sleeping quality according to PSQI total score reveals that $95.9 \%$ of patients with hypertension suffered from poor sleeping quality and just only $4.9 \%$ of them were categorized as good sleeping quality. From the findings, we concluded that poor sleeping quality is a common phenomenon among hypertension patients in Nam Phong commune, Nam Dinh city. Therefore, we recommend that it is necessary to conduct intervention programs aiming at improving the sleeping quality of hypertension patients in Nam Phong commune, Nam Dinh city.

Keywords: sleeping quality, patients with hypertension, Nam Phong commune, Nam Dinh city

\section{I. ĐĂT VẤN ĐỀ}

Bênh tăng huyết áp (THA) là một trong những bệnh mạn tính phổ biến nhất trên thế giới và hiện đang góp phần đáng kể vào gánh nặng bệnh tật toàn cầu. Nhiều nghiên cứu đi trước đã chỉ ra rằng những người mắc THA thì có $\mathrm{CLGN}$ kém hơn so với nhóm đối tượng không mắc THA [5], [4]. Những triệu chứng của THA như đau đầu, đau ngực, chóng mặt, khó thở và chảy máu mũi thường dẫn tới CLGN kém ở người bệnh THA [7]. Hậu quả của việc suy giảm CLGN ở bệnh nhân THA là dẫn tới tằng nguy cơ các bệnh như béo phì, bệnh động mạch vành, rối loạn nhịp thở khi ngủ, hội chứng ngừng thở khi ngủ [8], [4]. Tỷ lệ bệnh nhân THA có CLGN kém khác nhau ở mối nghiên cứu, dao động từ 14,9-85,7 trên toàn cầu [4]. Tại Việt Nam, kết quả của Vũ Thị Minh Phượng cho thấy tỷ lệ mắc rối loạn giấc ngủ ở người bệnh THA là 87,2\% [1]. Tác giả Lê Việt Thắng nghiên cứu ảnh hưởng của THA lên tình trạng rối loạn giấc ngủ người bệnh suy thận mạn tính lọc máu chu kỳ, cho kết quả tỷ lệ người bệnh có CLGN kém là 95,5\% [2]. Từ các kết quả nghiên cứu nêu trên, ta thấy rằng tình trạng rối loạn giấc ngủ ở người bệnh THA là khá phổ biến. Các nghiên cũng chứng minh yếu tố kinh tế-xã hội và yếu tố văn hoá là những yễu tố có ảnh hưởng đến CLGN. Vì thế cần có những nghiên cứu cụ thể về CLGN ở những quần thể khác nhau, để cung cấp những thông tin hữu ích cho các chương trình can thiệp, giúp đỡ người bệnh THA nâng cao CLGN, từ đó cải thiện kết quả điêu trị THA và giúp phòng những biến chứng nă̆ng nề hơn của bênh. Xã Nam Phong thành phố Nam Định là một trong những đơn vị tiêu biểu trong việc triển khai phòng ngừa và quản lý bệnh không lây nhiễm. Trạm y tế xã Nam Phong đã và đang triển khai nhiểu chương trình hỗ trợ bệnh nhân THA, trong đó cải thiện CLGN là một trong những mục tiêu được chú trọng. Tuy nhiên, cho đến nay chưa từng có nghiên cứu hay khảo sát nào về CLGN được tiến hành tại xã Nam Phong. Nhằm mục đích nâng cao hiệu quả của chương trình hỗ trợ bệnh nhân THA tại đây, bài báo của chúng tôi nhẳm mục tiêu đánh giá chất lượng giấc ngủ của người bệnh được được chẩn đoán mắc THA tại địa bàn nghiên cứu.

\section{II. ĐỐl TƯƠNGG VÀ PHƯƠNG PHÁP NGHIÊN CỨU}

2.1. Đối tượng nghiên cứu. Người được chẩn đoán mắc THA đang sinh sống tại xã Nam Phong, thành phố Nam Định, theo danh sách được cung cấp bởi trạm y tể xã.

\subsection{Thời gian và địa điểm nghiên cứu}


Thời gian: từ tháng 2- tháng 8 năm 2019

Địa điểm nghiên cứu: tại xã Nam Phong, thành phố Nam Đinh

2.3. Thiết kế nghiên cứu. Nghiên cứu mô tả cắt ngang

2.4. Cỡ mẫu nghiên cứu. Chọn mẫu toàn bộ số người mắc THA được quản lý theo danh sách được cung cấp tại trạm y tế xã Nam Phong. Tổng số BN tăng HA được trạm cung cấp là 178 người. Tuy nhiên có 5 người không đủ tiêu chuẩn lựa chọn vào nghiên cứu, 20 người không liên hệ được và 5 người không đồng ý tham gia vào nghiên cứu. Vì vậy chúng tôi tiến hành phỏng vấn được tổng 148 đối tượng.

2.5. Công cụ nghiên cứu. Nghiên cứu sử dụng thang đánh giá CLGNPittsburgh Sleep Quality Index (PSQI) [10]. Bộ công cụ đã được dịch sang tiếng Việt và được xin ý kiến chuyên gia để điêu chỉnh từ ngữ cho sát nghĩa và phù hợp với điều kiện thực tế Việt Nam. Sau đó chúng tôi tiến hành phỏng vấn thử và đánh giá độ tin cậy bằng hê số Cronbach Anpha trên 30 người bệnh không liên quan đến cõ̃ mẫu nghiên cứu. Kết quả thu được hệ số Cronback Anpha = 0.85 , phù hợp để sử dụng trong nghiên cứu.

Thang đánh giá CLGN PSQI gồm14 câu hỏi dựa trên tần suất và mức độ của các vấn đề liên quan đến giấc ngủ dựa trên 7 phương diện: thời gian ngủ, tỉnh giấc giữa đêm, mức độ khó ngủ, hiệu suất giấc ngủ (tỷ lệ toàn bộ thời gian ngủ và thời gian nằm trên giường), mức độ ảnh hưởng đến hoạt động ban ngày do thiếu ngủ, sử dụng thuốc ngủ, tự đáng giá CLGN (theo ý chủ quan của đối tượng).

Tiêu chuẩn đánh giá: Tổng điểm mà người bệnh có thể đạt được dao động từ 0-21.

Tổng điểm PSQI $\leq 5$ được phân loại là CLGN tốt

Tổng điểm PSQI > 5 được phân loại CLGN kém.

Trong đó: Tổng điểm PSQI từ: 6- 10 = rối loạn giấc nhẹ, 11- 15 = rối loạn giấc ngủ trung bình, $>15$ = rối loạn giấc ngủ nặng

Mức điểm càng cao thì CLGN càng thấp.

2.6. Thu thập số liệu. Số liệu được thu thập bởi 10 điều tra viên là sinh viên trường Đại học điều dưỡng Nam Định. Điều tra viên được tập huấn kỹ càng trước khi chính thức đi phỏng vấn đối tượng và được giám sát trong suốt quá trình thu thập bởi nghiên cứu viên chính.

Cán bộ trạm y tế giúp điều tra viên liên hệ với người bệnh, sau đó điêu tra viên tới tận nhà người bệnh để phỏng vấn, sử dụng bộ công cụ đã được in ra trên khổ giấy A4. Sau đó điêuu tra viên phỏng vấn trực tiếp đối tượng. Thời gian trung bình cho mỗi cuộc phỏng vấn là 20 phút.
2.7. Quản lý và xử lý số liệu. Số liệu được nhập bằng phần mềm Epidata 3.0 sau đó được phẩn tích dưới phần mềm SPSS 22.0

III. KẾT QUẢ NGHIÊN CứU

Bảng 3.1: Đặc điểm nhân khẩu học

\begin{tabular}{|c|c|c|c|}
\hline \multicolumn{2}{|r|}{ Đặc điểm } & Số lương & Tỷ lê \\
\hline \multirow{5}{*}{ Tuổi } & $41-50$ & 9 & 6,1 \\
\hline & $51-60$ & 24 & 16,2 \\
\hline & $61-70$ & 58 & 39,2 \\
\hline & $71-80$ & 40 & 27,0 \\
\hline & $80-90$ & 17 & 11,5 \\
\hline \multirow{2}{*}{ Giới } & Nam & 73 & 49,3 \\
\hline & Nữ & 75 & 50,7 \\
\hline \multirow{5}{*}{$\begin{array}{l}\text { Trình } \\
\text { độ học } \\
\text { vấn }\end{array}$} & Tiếu học & 31 & 20,9 \\
\hline & Trung học cơ sở & 80 & 54,1 \\
\hline & $\begin{array}{l}\text { Trung học phố } \\
\text { thông }\end{array}$ & 20 & 13,5 \\
\hline & Trung cấp/cao đằng & 13 & 8,8 \\
\hline & $\begin{array}{c}\text { Đại học hoặc cao } \\
\text { hơn }\end{array}$ & 4 & 2,7 \\
\hline \multirow{4}{*}{$\begin{array}{c}\text { Tình } \\
\text { trâng } \\
\text { hôn } \\
\text { nhân }\end{array}$} & Độc thân & 9 & 6,1 \\
\hline & Kết hôn & 130 & 87,8 \\
\hline & Ly thân/ly dị & 1 & 0,7 \\
\hline & Goá & 8 & 5,4 \\
\hline \multirow{5}{*}{$\begin{array}{l}\text { Nghề } \\
\text { nghiệp }\end{array}$} & Nông dân & 101 & 68,2 \\
\hline & Công nhân & 10 & 6,8 \\
\hline & $\begin{array}{l}\text { Kinh doanh buôn } \\
\text { bán }\end{array}$ & 12 & 8,1 \\
\hline & $\begin{array}{l}\text { Người già không } \\
\text { chê độ hưu }\end{array}$ & 1 & 0,7 \\
\hline & $\begin{array}{c}\text { Cán bộ cồng nhân } \\
\text { hưu }\end{array}$ & 24 & 16,2 \\
\hline \multirow{4}{*}{$\begin{array}{l}\text { Thu } \\
\text { nhập } \\
\text { bình } \\
\text { quân }\end{array}$} & <2 triệu/ tháng & 46 & 31,1 \\
\hline & $\begin{array}{c}\text { 2- dưới } 3 \text { triệu/ } \\
\text { tháng }\end{array}$ & 65 & 43,9 \\
\hline & $\begin{array}{l}\text { 3- dưới } 4 \text { triệu/ } \\
\text { tháng }\end{array}$ & 22 & 14,9 \\
\hline & $>=4$ triệu/ tháng & 15 & 10,1 \\
\hline \multirow{4}{*}{$\begin{array}{l}\text { Thời } \\
\text { gian } \\
\text { mắc } \\
\text { THA }\end{array}$} & 1-5 năm & 55 & 37,2 \\
\hline & 6-10 năm & 62 & 41,9 \\
\hline & $11-20$ năm & 15 & 10,1 \\
\hline & >20 năm & 3 & 2,0 \\
\hline
\end{tabular}

Bảng 3.1 cung cấp thông tin về đặc điểm của đối tượng nghiên cứu. Đối tượng nghiên cứu của chúng tôi chủ yếu tập trung từ 51-80 tuổi: Nhóm đối tượng từ 61-70 chiếm tỷ lệ cao nhất là $39,2 \%$. Nhóm đối tượng từ 71-80 tuổi chiếm tỷ lệ thấp hơn là $27 \%$. Tỷ lệ nam và nữ tương đối đồng đều, lần lượt là 49,3\% và $50,7 \%$. Phần lớn đối tượng có trình độ học vấn là trung học cơ sở, chiếm $54,1 \%$. Tình trang hôn nhân đã kết hôn chiếm tỷ lệ cao nhất là $87,8 \%$. Nghề nghiệp chủ yếu là nông dân, chiếm $68,2 \%$. Thu nhập bình quân phần lớn dưới 3 triệu/tháng. Thời gian mắc 
THA từ 1-5 năm chiếm $37,2 \%$ và từ $6-10$ năm chiếm $41,9 \%$.

Bảng 3.2. Tiêu chí đánh giá chất lượng giấc ngư theo thang điểm PSQI

\begin{tabular}{|c|c|c|c|}
\hline \multicolumn{2}{|c|}{ Tiêu chí đánh giá CLGN theo } & \multirow{2}{*}{\begin{tabular}{|c|}
$\begin{array}{c}\text { Số } \\
\text { lượng }\end{array}$ \\
34
\end{tabular}} & Tỷ lệ \\
\hline \multirow{4}{*}{$\begin{array}{l}\text { Thời gian } \\
\text { đì vào } \\
\text { giấc ngủ }\end{array}$} & 15 phút & & 23 \\
\hline & $15<$ đến 30 phút & 73 & 49,3 \\
\hline & $30<$ đến 60 phút & 40 & 27 \\
\hline & $>60$ phút & 1 & 0,7 \\
\hline \multirow{4}{*}{$\begin{array}{c}\text { Thời gian } \\
\text { ngử } \\
\text { trong } \\
\text { một đêm }\end{array}$} & $\geq 7$ & 14 & 9,5 \\
\hline & 6-7 tiếng & 32 & 21,6 \\
\hline & 5-6 tiếng & 47 & 31,8 \\
\hline & $<5$ tiếng & 55 & 37,2 \\
\hline \multirow{4}{*}{$\begin{array}{l}\text { Mức độ } \\
\text { khó ngủ }\end{array}$} & Không khó ngủ & 9 & 6,1 \\
\hline & Hơi khó ngủ & 49 & 33,1 \\
\hline & Khó ngủ & 77 & 52 \\
\hline & Rất khó ngủ & 13 & 8,8 \\
\hline \multirow{3}{*}{$\begin{array}{l}\text { Tỉnh giấc } \\
\text { giữa đêm }\end{array}$} & Không tỉnh giấc & 93 & 62,8 \\
\hline & Thi thoảng & 54 & 36,5 \\
\hline & Thường xuyên & 1 & 0,7 \\
\hline \multirow{4}{*}{$\begin{array}{l}\text { Hiệu suất } \\
\text { giấc ngư }\end{array}$} & $\geq 85 \%$ (tốt) & 28 & 18,9 \\
\hline & $75-<85 \%$ (trung bình) & 31 & 20,9 \\
\hline & $\begin{array}{c}65-<75 \% \text { (tương đối } \\
\text { kém) }\end{array}$ & 30 & 20,3 \\
\hline & $\leq 65 \%$ (kém) & 59 & 39,9 \\
\hline \multirow{4}{*}{$\begin{array}{l}\text { Mức độ } \\
\text { sứ dựng } \\
\text { thuốc } \\
\text { ngủ } \\
\text { trong } 1 \\
\text { tuần }\end{array}$} & không lần nào & 71 & 48 \\
\hline & ít hơn1 lần/tuần & 29 & 19,6 \\
\hline & 1 hoặc 2 lần/tuân & 18 & 12,2 \\
\hline & từ 3 lần trở lên & 30 & 20,3 \\
\hline \multirow{4}{*}{$\begin{array}{l}\text { Mức độ } \\
\text { ảnh } \\
\text { hưởng } \\
\text { đến hoạt } \\
\text { động ban } \\
\text { ngày do } \\
\text { thiếu ngủ }\end{array}$} & không gặp khó khăn gì & 0 & 0 \\
\hline & $\begin{array}{l}\text { gặp khó khăn một } \\
\text { chút }\end{array}$ & 33 & 22,3 \\
\hline & $\begin{array}{c}\text { gặp khó khăn ở mức } \\
\text { độ nhẹ }\end{array}$ & 79 & 53,4 \\
\hline & mức độ khó khăn lớn & 36 & 24,3 \\
\hline \multirow{4}{*}{$\begin{array}{l}\text { Tự đánh } \\
\text { giá CLGN }\end{array}$} & rất tốt & 9 & 6,1 \\
\hline & tương đối tốt & 55 & 37,2 \\
\hline & tương đối kém & 79 & 53,4 \\
\hline & rất kém & 5 & 3,4 \\
\hline
\end{tabular}

Bảng 3.2 miêu tả các nội dung chính được đánh giá trong bộ công cụ PSQI. Gần một nửa số đối tượng được hỏi $(49,3 \%)$ cho biết, họ mất từ 15 tới 30 phút để đi vào giấc ngủ. Có $27 \%$ đối tượng có thể bắt đầu ngủ sau 30-60 phút.

Thời gian ngủ ít hơn 5 tiếng mỗi đêm chiếm tỷ lệ cao nhất ở bệnh nhân THA được phỏng vấn, 37,2\%; ngủ được 5-6 tiếng chiếm 31,8\%; ngủ được 6-7 tiếng chiếm 21,6\%. Tỷ lệ đối tượng ngủ được nhiều hơn 7 nhỏ nhất là $9,5 \%$.

Về mức độ khó ngủ, có $52 \%$ ở mức độ khó ngủ, và $33,1 \%$ ở mức độ hơi khó ngủ. Vể tỉnh giấc giữa đêm, có $36,5 \%$ bệnh nhân THA có tỉnh giấc giữa đêm. Hiệu suất giấc ngủ ở mức độ kém chiếm tỷ lệ cao nhất là 39,9\%, trong khi hiệu suất giấc ngủ tốt chỉ chiếm tỳ lệ nhỏ nhất là 18,9\%. Có $52 \%$ đối tượng được hỏi phải sử dụng thuốc ngủ trong 1 tuần, trong đó tỷ lệ dùng thuốc ngủ từ 3 lần trở lên trong 1 tuần chiếm tỷ lê $20,3 \%$.

Có 54,4\% đối tượng được hỏi trả lời rằng việc thiếu ngủ về ban đềm khiển họ gặp khó khăn ở mức độ nhe trong những hoạt động vào ban ngày và $24,3 \%$ cho rằng ho găp khó khăn ở mức độ lớn. Khi được hỏi về tự đánh giá CLGN của bản thân, có $53,4 \%$ đánh giá CLGN ở mức tương đối kém và $37,2 \%$ đánh giá mình có giấc ngủ tương đối tốt.

Bảng 3.3. Phân loại chất lượng giấc ngủ theo thang điểm PSQI

\begin{tabular}{|c|c|c|c|}
\hline \multicolumn{2}{|c|}{ Chất lương aiấc nqủ } & $\begin{array}{c}\text { Số } \\
\text { lượng }\end{array}$ & $\begin{array}{l}\text { Tỷ } \\
\text { lệ }\end{array}$ \\
\hline \multicolumn{2}{|r|}{ CLGN tốt ( $\leq 5$ điểm) } & 6 & 4,1 \\
\hline \multicolumn{2}{|r|}{ CLGN kém } & 142 & 95,9 \\
\hline \multirow{3}{*}{$\begin{array}{l}\text { CLGN } \\
\text { kém }\end{array}$} & RLGN nhẹ(6-10 điếm) & 53 & 35,8 \\
\hline & $\begin{array}{l}\text { RLGN trung bình } \\
(11-15 \text { điểm) }\end{array}$ & 74 & 50 \\
\hline & $\begin{array}{l}\text { RLGN năng } \\
\text { (>15 điểm) }\end{array}$ & 15 & 10,1 \\
\hline
\end{tabular}

Kết quả đánh giá CLGN theo thang phân loại PSQI cho thấy, có 95,9\% đối tượng được hỏi được phân loai là có CLGN kém và chỉ có $4.1 \%$ có CLGN tốt. Trong đó $\mathrm{BN}$ mắc THA có RLGN nhe chiếm $35,8 \%$, RLGN trung bình chiếm $50 \%$ và RLGN nặng chiếm $10,1 \%$.

\section{BÀN LUÂN}

Trong kết quả nghiên cứu của chúng tôi, có gần một nửa số người bệnh THA cần từ 15-30 phút mới có thể đi vào giấc ngủ và $27 \%$ số người bệnh THA cần từ 30-60 phút để đi vào giấc ngủ. Nghiên cứu của chúng tôi cho kết quả tương tự với nghiên cứu của tác giả Lê Việt Thắng và cộng sự, khi nghiên cứu trên đối tượng tăng huyết áp có suy thận mạn tính lọc máu chu kỳ cho kêt quả một tỷ lệ đáng kể những BN THA kèm suy thận mạn cảm thây khó khăn khi đi vào giấc ngủ [2]. Kết quả này cũng tương tự như tác giả Vũ Thị Minh Phượng với $56,8 \%$ bệnh nhân THA cảm thây không thể ngủ được trong vòng 30 phút, với tần suất nhiều hơn 3 lần/tuần [1].

Ngoài ra có $1 / 3$ tỷ lệ đối tượng có thời lượng ngủ ban đêm < 5 tiếng/đêm với thời gian ngủ trung bình/đêm của nhóm đối tượng này tương đối thấp $=3,7 \pm 0,7$ tiếng. Thời gian ngủ tốt nhất vào ban đêm để duy trì một sức khoẻ tốt là 
từ 7-8 tiêng/đêm. Đây là chu kỳ ngủ tốt nhất mang lại rất nhiều lợi ích về sức khoẻ, so với việc ngủ ít hơn hoặc nhiều hơn [3]. Nhiều nghiên cứu đã chỉ ra khá nhiều việc tác động có hại cho sức khoẻ ở nhóm người trưởng thành có thời gian ngủ <5 tiếng/đêm hoặc từ 5-6 tiếng/đêm, bao gồm có nguy cơ cao dẫn tới mắc bệnh tăng huyết áp, trầm cảm, béo phì,...Việc ngủ không đủ giấc ở những người mắc THA mang lại nhiều nguy cơ về sức khoẻ hơn so với nhóm người khoẻ manh. Nghiên cứu của Paola Lusardi và cộng sự đã chỉ ra rằng thiếu ngủ ở bệnh nhân THA có thể làm tăng hoạt động của thần kinh giao cảm trong đêm và sáng hôm sau, dẫn đến THA và nhịp tim và buổi sáng, và làm tăng tổn thương cơ quan đích và các bênh tim mach mãn tính [6]. Ở đối tượng THA, các triệu chứng của THA như đau đầu, đau ngực, mệt mỏi,... có thể là nguyên nhân dẫn tới việc họ cảm thấy khó ngủ hơn vào ban đêm [4], và việc không ngủ được vào ban đêm lại dẫn tới tình trạng THA trở nên trầm trọng hợn. Vì vậy việc hướng dẫn người bệnh có thực hành vệ sinh giấc ngủ và kết hợp một số các biện pháp khác nhau để nâng cao CLGN vào ban đêm là điều cần chú trọng trong điều trị và chăm sóc bệnh nhân THA.

Ngoài ra việc thời gian ngủ không đủ, thiếu ngủ, CLGN không tốt dẫn tới cảm giác mệt mỏi, giảm tỉnh táo và năng động trong các hoạt động hàng ngày ở người bệnh THA. Trong nghiên cứu của chúng tôi có hơn môt nửa bênh nhân THA cho rằng mình gặp khó khăn ở mức độ nhẹ và gần $1 / 5$ đối tượng cho rằng mình gặp khó khăn ở mức độ nặng do tình trạng thiếu ngủ về ban đêm. Trong nghiên cứu của Lê Viê̂t Thắng cũng chỉ ra có sự khác biệt có ý nghĩa thống kê giữa nhóm tăng huyết áp có suy thận mạn và nhóm chứng; nhóm THA cảm thây khó khăn hơn trong các hoạt động hàng ngày do CLGN không tốt [2]. Kết quả nghiên cứu của chúng tôi cao hơn so với kết quả của Vũ Thị Minh Phượng (khi đánh giá ở nhóm đối tượng tương tự và sử dụng cùng thang PSQI): có 60,8\% đối tượng không gặp khó khăn gì trong các hoạt động ban ngày và $29,8 \%$ cho rằng mình chỉ gặp một chút khó khăn [1].

Trong nghiên cứu của chúng tôi có hơn một nửa số bệnh nhân THA (52\%) có sử dụng thuốc ngủ để giúp cải thiện tình trạng THA. Việc sử dụng thuốc ngủ, đặc biệt là sử dụng thường xuyên ở người bệnh THA là không được khuyến cáo, do các tác dụng phụ nghiêm trọng mà thuốc ngủ mang tới tới sức khoẻ tim mạch, đặc biệt làm tăng nguy cơ đau tim, làm tình trạng THA trở nên nặng nề hơn[9].
CLGN có thể được đánh giá bằng một số công cụ khác nhau, tuy nhiên thang đo PSQI là thang đo được đánh giá là thuận tiện và có nhiêu ưu điểm hơn. Kết quả nghiên cứu của chúng tôi cho thấy tỷ lệ đối tượng có rối loạn giấc ngủ chiếm tỷ lệ cao, chiếm 95,9\%. Kết quả nghiên cứu của chúng tôi cho kết quả tương tự so với nghiên cứu của Lê Việt Thắng, với cùng sử dụng thang đo PSQI trên bệnh nhân THA. Kết quả này cao hơn so với kết quả trong nghiên cứu của Vũ Thị Minh Phượng (87,2\% người bệnh THA có điểm $P S Q I>5$ ). Kết quả này cũng cao hơn so với tác giả LinLi và cộng sự khi tiến hành trên những người bệnh THA tại Trung Quốc, với tỷ lệ $52,5 \%$ BN THA có CLGN kém [4]. Qua kết quả từ các nghiên cứu gần đây cho thấy, tình trạng rối loạn giấc ngủ hay CLGN kém là phổ biến ở bệnh nhân THA, tuy nhiên tỷ lệ bệnh nhân THA có CLGN kém là khác nhau ở các nghiên cứu. Điều này có thể do CLGN còn chịu ảnh hưởng của nhiều yếu tố khác, ví dụ như yểu tố kinh tế-xã hội và tôn giáo[4]. Nghiên cứu của chúng tôi cho kết quả cao hơn những nghiên cứu khác có thể do trong nghiên cứu của chúng tôi phần lớn BN ở độ tuổi cao, từ 51-90 tuổi (bảng 3.1), và đã mắc THA lâu năm, nên ảnh hưởng của tình trạng THA lên giấc ngủ có thể rõ ràng hơn. Bên cạnh đó, trong nghiên cứu của chúng tôi phần lớn đối tượng là nông dân, với thu nhập dưới 3 triệu đồng/tháng. Yếu tố thu nhập cá nhân và nghề nghiệp có thể là một trong những yếu tố kích thích cảm giác lo lắng, khiến đối tượng mất ngủ nhiều hơn so với những nhóm đối tượng khác.

\section{KẾT LUÂ̂N}

Những người mắc THA tại xã Nam Phong, thành phố Nam Định có CLGN kém chiếm 95,9\% và $C L G N$ tốt chiếm tỷ lệ thấp hơn là $4,1 \%$, theo thang phân loại PSQI về CLGN. Từ đó chúng tôi kết luận CLGN kém là hội chứng thường gặp ở những người mắc THA tại xã Nam Phong, thành phố Nam Định, vì thế cần có các biện pháp can thiệp và hố trợ phù hợp để nâng cao CLGN ở nhóm đối tượng kể trên.

\section{TÀI LIỆU THAM KHẢO}

1. Vũ Thị Minh Phượng (2016), Chất lượng giấc ngủ và một số yếu tô liên quan của người bệnh tăng huyết áp điều trị ngoại trú tại bệnh viện đa khoa tỉnh Nam Định năm 2016, Luận văn Thạc sỹ điêu dưỡng, Trường Đai hoc điều dưỡng Nam Định.

2. Lê Việt Thắng (2012) I Ảnh hưởng của tăng huyết áp lên tình trạng rối loạn giấc ngủ bệnh nhân suy thận mạn tính lọc máu chu kỳ. Tạp chí Y học thực hành, 813 (3/2012). 
3. Grandner M., Mullington J.M., Hashmi S.D. và cộng sự. (2018). Sleep Duration and Hypertension: Analysis of > 700,000 Adults by Age and Sex. J Clin Sleep Med, 14(6), 1031-1039.

4. Li L., Li L., Chai J.-X. và cộngsự. (2020). Prevalence of Poor Sleep Quality in Patients With Hypertension in China: A Meta-analysis of Comparative Studies and Epidemiological Surveys. Front Psychiatry, $\mathbf{1 1}$.

5. Liu R.-Q., Qian Z., Trevathan E. và côngsứ, (2016). Poor sleep quality associated with high risk of hypertension and elevated blood pressure in
China: results from a large population-based study. Hypertens Res, 39(1), 54-59.

6. Lusardi P. Zoppi A., Preti P. và công sư. (1999). Effects of insufficient sleep on blood pressure in hypertensive patients: A 24-h study. American Journal of Hypertension, 12(1), 63-68.

7. Organization W.H. (2013). A global brief on hypertension: silent killer, global public health crisis: World Health Day 2013. .

8. Silverberg D.S. và Oksenberg A. (2001). Are sleep-related breathing disorders important contributing factors to the production of essential hypertension?.CurrHypertens Rep, 3(3), 209-215.

\section{KẾT QUẢ NEPP VÍT QUA CUỐNG ĐÎ̀̀U TRI GÃY CộT SỐNG ĐOẠN BẢN LỀ NGỰC THẮT LƯNG MẤT VỮNG TẠI BÊ̂NH VIỆN ĐA KHOA TİNH NINH BÌNH}

\section{TÓM TẮT}

Mục tiêu: Nhận xét kết quả nẹp vít qua cuống điều trị gãy cột sống đoạn bản lề ngực thắt lưng mất vững tai Bênh viên Đa khoa tỉnh Ninh Bình. Phương pháp: Mô tả cắt ngang 112 bệnh nhân gãy cột sống đoạn bản lề ngực thắt lưng mất vững, không có tổn thương thần kinh. Kết quả: 112 bệnh nhân (53 nam, 59 nữ); tuổi trung bình 52,2 (từ 15 đến 71 tuổi); Triệu chứng lâm sàng đau lưng $100 \%$; sưng nề 55,4\%; tụ máu $15,2 \%$; co cơ cạnh cột sống $34,8 \%$; Vị trí tổn thương hay gặp nhất là L1: 47,9\%; Đặc điểm tổn thương trên cằt lớp vi tính: Vơ thân đổt $100 \%$; võ cuống sống: $8,9 \%$; võ cung sau: $28,6 \%$; gãy mỏm gai: $7,1 \%$; gãy mỏm ngang: $10,7 \%$; Hiệu quả nắn chỉnh cột sống: Góc gù thân đốt và góc gù̀ vùng chân thương trung bình sau mổ đều giảm có ý nghĩa thống kê $(p<0,001)$ so với trước mổ. Tỷ lê giảm góc gù thân đốt trung bình đạt 72,6\%; Tỷ lệ nhiểm trùng vết mổ chiếm $1,8 \%$. Kết quả sau phẫu thuật 6 tháng theo thang điểm Denis về mức độ đau và khả năng trở lại lao động đều đat mức độ tốt. Kết luân: Phẫu thuẩt nẹp vít qua cuống điều trị gãy cột sông đoạn bản lề ngực thắt lưng mất vững cho hiệu quả nắn chỉnh cột sống cao và bệnh nhân hồi phục tốt.

Tư khóa: gãy cột sống ngực thắt lưng, nẹp vít qua cuống

\section{SUMMARY \\ OUTCOMES OF TRANSPEDICULAR SCREW FIXATION IN THE TREATMENT OF UNSTABLE THORACOLUMBAR VERTEBTAL FRACTURES}

\footnotetext{
*Bệnh viện $Đ K$ tỉnh Ninh Binh

**Trường Đại học Y Dược Thái Binh

Chịu trách nhiệm chính: Vũ Minh Hải

Email: vuminhhai777@gmail.com

Ngày nhận bài: 5.5.2021

Ngày phản biện khoa học: 24.6.2021

Ngày duyệt bài: 5.7.2021
}

\section{Phạm Thế Tráng*, Vũ Minh Hải**}

Objectives: To evaluate the outcomes of transpedicular screw fixation in the treatment of unstable thoracolumbar vertebral fractures at Ninh Binh General Hospital. Methods: A cross-sectional descriptive study was conducted among 112 patients with unstable thoracolumbar vertebral fractures without neurological deficits. Results: 112 patients (53 males, 59 females); median age was 52.2 (from 15 to 71 years old); Clinical manifestations: back pain accounted for $100 \%$; swelling $55.4 \%$; hematoma $15.2 \%$; paraspinal muscle spasm $34.8 \%$; The most common site of injuries was L1: $47.9 \%$; Fractures were seen on CT: Vertebral body $100 \%$; pedicle: 8.9\%; lamina: $28.6 \%$; Spinous process: $7.1 \%$ transverse process: $10.7 \%$; The effectiveness of spinal fracture reduction: The local and segmental kyphotic angle of injured segment were significantly reduced $(p<0.001)$ in the pre and postoperarive comparison statistically. The average reduction rate of local kyphotic angle reached $72.6 \%$; The rate of surgical site infection accounted for $1.8 \%$. The outcomes at 6 month postoperatively according to the Denis pain and work scale attained good level. Conclusion: Transpedicular screw fixation of unstable thoracolumbar vertebral fractures gives patients high efficiency of spinal correction and good recovery.

Keywords: thoracolumbar vertebral fracture; pedicle screw plate fixation.

\section{I. ĐĂT VẤN ĐỀ}

Chấn thương cột sống đoạn bản lề ngực-thắt lưng là một cấp cứu thường gặp. Chấn thương cột sống đoạn bản lề ngực-thắt lưng chiếm khoảng $70 \%$ tổng số chấn thương cột sống. Chấn thương cột sống đoạn ngực-thắt lưng mất vững, đơn thuần mặc dù không có khiếm khuyết thân kinh nhưng nểu không được điêuu trị đúng cũng có thể gây ra những di chứng bị đau lưng 